\title{
KAJIAN KUALITAS PERAIRAN UNTUK BUDIDAYA UDANG DI KABUPATEN SUBANG
}

\author{
Oleh: \\ Iis Jubaedah, Dinno Sudinno dan Pigoselpi Anas \\ Dosen Jurusan Penyuluhan Perikanan Sekolah Tinggi Perikanan
}

\begin{abstract}
ABSTRAK
Kajian kualitas perairan pesisir di Kabupaten Subang bertujuan untuk mengetahui kualitas perairan di Kawasan Pesisir Subang dan kelayakannya untuk kegiatan budidaya udang serta mengetahui perkembangan produksi udang dikaitkan dengan kualitas air. Metode yang digunakan dalam penelitian ini adalah metode survei. Data yang digunakan untuk kajian kualitas perairan mencakup data primer dan data sekunder. Proses analisa data yang dilakukan meliputi analisa kualitas air, analisa status mutu air, analisa indeks diversitas plankton, dan menduga produksi udang. Hasil kajian menunjukkan, nilai indeks pencemaran 2,2491 artinya wilayah pesisir Kabupaten Subang termasuk tercemar ringan, namun masih layak digunakan sebagai sumber air untuk kegiatan budidaya ikan di tambak. Dari estimasi perhitungan potensi perikanan didapatkan laju perikanan potensial rata-rata sekitar 0,13333 ton/ha/tahun. Dengan luas tambak seluas 14.300 ha maka diperkirakan potensi produksi udang Kabupaten Subang sebesar 1906,6 ton/tahun.
\end{abstract}

Kata kunci: kualitas air, budidaya udang, Kabupaten Subang.

\section{PENDAHULUAN}

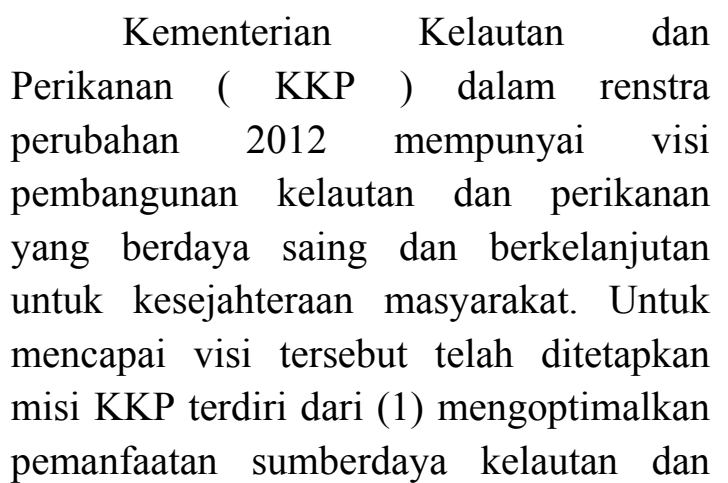

perikanan, (2) meningkatkan nilai tambah dan daya saing produk kelautan dan perikanan, serta (3) memelihara daya dukung dan kualitas lingkungan sumberdaya kelautan dan perikanan.

Perkembangan perikanan budidaya dalam dasawarsa terakhir memperlihatkan peningkatan yang pesat, maka perikanan budidaya memiliki peran penting dan diharapkan menjadi jaminan masa depan bagi ketahanan pangan masyarakat 
Indonesia. Upaya peningkatan produksi perikanan budidaya tidak terlepas dari berbagai kendala yang menyebabkan produksi berfluktuatif. Dari berbagai kajian diperoleh, salah satu penyebab menurunnya produksi budidaya udang di pantai Utara Jawa adalah menurunnya kualitas lingkungan perairan.

Salah satu penyebab menurunnya kualitas lingkungan perairan adalah limbah budidaya yang berasal dari sisa pakan dan feses yang terlarut ke dalam air ( Rachman Syah, 2006 ). Selanjutnya dikatakan bahwa budidaya udang vaname pada tambak skala kecil dengan luas 1000 $\mathrm{m}^{2}$ dengan padat penebaran 650 ekor $/ \mathrm{m}^{2}$ diperkirakan menghasilkan beban limbah organik sebanyak 4,8 ton dengan asumsi sekitar 35\% pakan tidak dimakan oleh udang. Fenomena ini merupakan konsekuensi dari pengembangan kegiatan budidaya tambak yang mengabaikan aspek daya dukung lingkungan dan mengalokasikan input teknologi pada kondisi di atas batas daya dukung lingkungan hanya untuk mengejar target keuntungan maksimal dalam waktu yang cepat. Oleh karena itu dalam penelitian ini, penulis akan mengkaji kualitas lingkungan perairan kawasan perairan pesisir Kabupaten Subang. Penelitian ini menjadi sangat relevan disebabkan oleh kegiatan manusia di darat menyebabkan pencemaran pada perairan yang akan mempengaruhi produksi dan kesejahteraan masyarakat pesisir.

\section{Tujuan}

Tujuan penelitian ini adalah :

1. Mengetahui kualitas perairan di kawasan Pesisir Subang dan kelayakannya untuk kegiatan budidaya udang di tambak.

2. Mengetahui perkembangan produksi udang Kabupaten Subang dikaitkan dengan kualitas air

\section{METODE}

\section{Tempat dan waktu penelitian}

Penelitian dilakukan di Perairan

Pesisir Kabupaten Subang pada bulan Mei sampai dengan Agustus 2012.

\section{Metode Penelitian}

Metode yang digunakan dalam penelitian ini adalah metode survei. Pengamatan dilakukan pada 8 (delapan) stasiun pengamatan, yaitu :

Stasiun 1 (St.1) : wilayah banyak mangrove

Stasiun 2 (St.2) : wilayah tinggi gelombang $4-42 \mathrm{~cm}$

Stasiun 3 (St.3) : wilayah berbentuk teluk banyak terjadi proses pengendapan sedimen

Stasiun 4 (St.4) : wilayah rata-rata kedalaman $<5 \mathrm{~m}$

Stasiun 5 (St 5) : wilayah sedikit mangrove 

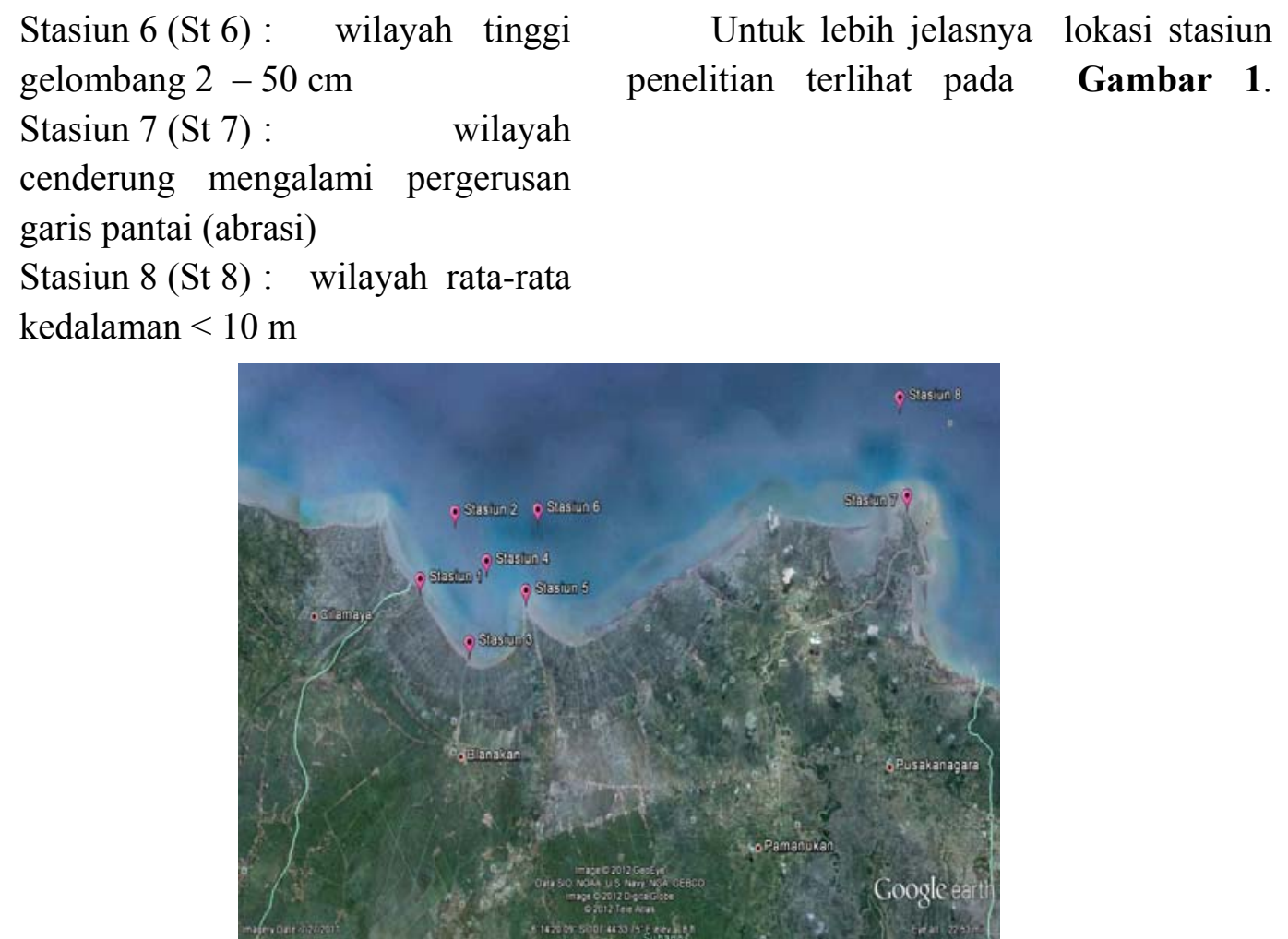

Gambar 1. Lokasi Stasiun Penelitian.

\section{Pengumpulan data}

Data yang digunakan dalam penelitian ini adalah data primer dan data sekunder. Data primer diperoleh melalui survei langsung di lapangan. Untuk mengumpulkan data sebagai berikut :

\section{Parameter Fisika dan Kimia}

Untuk mendapatkan data kualitas air dilakukan pengukuran parameter fisika dan kimia langsung dilapangan dan mengambil sampel air untuk diuji dilaboratorium.

\section{Parameter Biologi}

Untuk mendapatkan contoh plankton, air sebanyak kurang lebih 50 liter disaring menggunakan plankton net No 25 menjadi $50 \mathrm{ml}$ dan diawetkan dengan lugol. Identifikasi jenis dilakukan di laboratorium menggunakan mikroskop dan buku identifikasi

Data sekunder diperoleh melalui kajian terhadap laporan - laporan hasil penelitian, publikasi ilmiah, peraturan perundang-undangan dan publikasi daerah. Data tersebut berasal dari instansi pemerintah maupun swasta yang 
mempunyai relevansi dengan tujuan penelitian meliputi :

- Data produksi udang tahun 2006 -2011 (Dinas kelautan dan perikanan Kabupaten Subang)

- Hubungan total suspension solved (TSS) dengan kandungan klorofil a (Sapto 2007)

- Hubungan kelimpahan Plankton dengan Klorofil a (Handayani dan Patria 2005)

- Data hidro-oceanografi (BMG)
Analisa data yang dilakukan meliputi analisa kualitas air, analisa status mutu air, analisa indeks diversitas plankton dan produksi udang.

\section{Analisa kualitas air}

Parameter dan cara analisis parameter físika dan kimia air, sebagaimana disajikan pada Tabel 1.

\section{Analisa data}

Tabel 1. Parameter dan Cara Analisis Kualitas Air

\begin{tabular}{|c|l|c|l|c|}
\hline No & \multicolumn{1}{|c|}{ Parameter } & Satuan & \multicolumn{1}{|c|}{ Alat/Cara Analisis } & Keterangan \\
\hline A. & Fisika & & & \\
\hline 1. & Kecerahan & $\mathrm{Cm}$ & Secchi disk & In situ \\
\hline 2. & Suhu & ${ }^{\circ} \mathrm{C}$ & Thermometer & In situ \\
\hline 3. & $(\mathrm{TSS})$ & $\mathrm{mg} / 1$ & Gravimetri & Laboratorium \\
\hline B. & Kimia & & & \\
\hline 4. & $\mathrm{pH}$ & - & $\mathrm{pH}$ meter & In situ \\
\hline 5. & Salinitas & $\mathrm{mo} / 1$ & Refraktometer & DO situ \\
\hline 6. & Oksigen terlarut & $\mathrm{mg}$ meter & In situ \\
\hline 7. & BOD & $\mathrm{mg} / 1$ & Botol sampel ; Titrimetrik & Laboratorium \\
\hline 8. & COD & $\mathrm{mg} / 1$ & Botol sampel; Titrimetrik & Laboratorium \\
\hline C & Biologi & & & \\
\hline & Plankton & Sel/liter & Plankton net no 25 & Laboratorium \\
\hline & & & & \\
\hline
\end{tabular}

\section{Status Mutu Air}

Pedoman yang digunakan untuk mengetahui status mutu air adalah Keputusan Menteri Negara Lingkungan Hidup Nomor : 115 Tahun 2003 tentang Pedoman Penentuan Status Mutu Air, disebutkan bahwa Indeks Pencemaran (IP) adalah indeks yang digunakan untuk menentukan tingkat pencemaran relatif terhadap parameter kualitas air yang diizinkan. Indeks ini memiliki konsep yang berlainan dengan Indeks Kualitas Air. Indeks Pencemaran ditentukan untuk suatu peruntukan, kemudian dapat dikembangkan untuk beberapa peruntukan bagi seluruh bagian badan air atau 
sebagian dari suatu perairan. Nilai Indeks Pencemaran dapat dihitung dengan rumus

$$
\mathbf{I} \mathbf{P}_{\mathbf{x}}=\frac{\sqrt{ }\left(\mathbf{C i} / \mathbf{L} \mathbf{i}_{\mathbf{x}}\right)^{2}{ }_{M}+\left(\mathbf{C i} / \mathbf{L} \mathbf{i}_{\mathbf{x}}\right)^{2} \mathbf{R}}{2}
$$

Keterangan :

IPx $=$ Indeks Pencemaran peruntukan air (x), $\quad \mathbf{C i}=$ Konsentrasi parameter kualitas air (i) dari suatu perairan yang akan dinilai, Lix $=$ Konsentrasi parameter sesuai baku mutu air peruntukan (x); $\mathbf{M}=$ Maksimum; $\mathbf{R}=$ Rata-rata

Evaluasi terhadap nilai Indeks Pencemaran adalah : a) $0 \leq \mathrm{IP} \leq 1,0=$ Memenuhi baku mutu (kondisi baik); b) $1,0<\mathrm{IP} \leq 5,0=$
Cemar ringan; c) 5,0 $<\mathrm{IP} \leq 10,0=$ Cemar sedang d) IP $>10,0=$ Cemar berat.

\section{Indeks Diversitas Plankton}

Analisa terhadap plankton dilakukan dengan menghitung nilai indeks diversitas plankton dengan Shannon Wieners formula (Soegianto, 2004) :

$$
\mathbf{H}=-\sum \mathbf{n}_{\mathbf{i}} / \mathbf{N} \ln \mathbf{n}_{\mathbf{i}} / \mathbf{N}
$$

Shannon dan Weiner dalam Soegianto, 2004 menyatakan bahwa berdasarkan indeks diversitas $\left(\mathrm{H}^{\prime}\right)$, kualitas air dikelompokkan atas 5 kategori seperti yang terdapat pada Tabel 2.

Tabel 2. Kriteria kualitas air berdasarkan indeks diversitas ( $\left.\mathbf{H}^{\prime}\right)$

\begin{tabular}{|c|c|}
\hline Indeks Diversitas & Kriteria kualitas air \\
\hline$<1,00$ & Sangat Rendah \\
\hline $1,00-1,66$ & Rendah \\
\hline $1,67-2,33$ & Sedang \\
\hline $2,34-3,00$ & Baik \\
\hline$>3,00$ & Sangat Baik \\
\hline
\end{tabular}

Sumber : Shannon dan Weiner dalam Soegianto (2004)

\section{Perhitungan Produksi Udang}

Untuk pendugaan Produksi udang didasarkan pada :

- Hubungan TSS dengan Klorofil a

- Hubungan kelimpahan Plankton dengan klorofil a
Selanjutnya nilai klorofil a di konversi menjadi produksi mikroalga yang merupakan konversi laju produksi mikroalga yang dikalikan dengan Ekotropik Efisiensi (EE) untuk mendapatkan jumlah mikroalga yang dikonsumsi oleh predatornya. Pada perhitungan ini asumsi yang digunakan adalah EE bernilai 0,279. Proses selanjutnya adalah mengalikan hasil 
perhitungan sebelumnya dengan koefisien 0.007 untuk mengubah biomass mikroalga menjadi biomass udang (Martinez-Goss, 1999) dalam Sapto (2008).

\section{HASIL DAN PEMBAHASAN}

\section{Kondisi Umum Wilayah}

Kabupaten Subang secara geografis terletak di bagian utara provinsi Jawa Barat yaitu antara $107^{\circ} 31^{\prime}-107^{\circ} 54^{\prime}$ BT dan $6^{\circ} 11^{\prime}-6^{\circ} 49^{\prime}$ LS. Batas-batas wilayah sebagai berikut :

- Sebelah selatan berbatasan dengan Kabupaten Bandung

- Sebelah barat berbatasan dengan Kabupaten Purwakarta dan Karawang

- Sebelah utara berbatasan dengan Laut Jawa

- Sebelah timur berbatasan dengan Kabupaten Indramayu dan Sumedang.

Luas Kabupaten Subang adalah 205.176,95 Ha (4,64\% dari luas Jawa Barat) dengan ketinggian antara $0-1500$ $\mathrm{m}$ dpl. Dilihat dari segi topografinya dapat dibedakan menjadi 3 zone daerah yaitu : Daerah pegunungan dengan ketinggian 500 - $1500 \mathrm{~m}$ dpl dengan luas 41.035,09 $\mathrm{Ha}(20 \%)$, daerah berbukit dengan ketinggian $50-500 \mathrm{~m}$ dpl dengan luas $71.502,16$ Ha $(35,85 \%)$, daerah dataran rendah dengan ketinggian $0-50 \mathrm{~m} \mathrm{dpl}$ dengan luas 92.939,7 Ha (45,15\%). Sekitar $80,8 \%$ Kabupaten Subang mempunyai kemiringan $\quad 0-17^{\circ} \mathrm{C}$, sedangkan sisanya memiliki kemiringan diatas $18^{\circ}$ C. Secara umum Kabupaten Subang beriklim tropis dengan curah hujan rata-rata pertahun $1593 \mathrm{~mm}$ dengan rata-rata hari hujan 91 hari.

Secara administrasi Kabupaten Subang terdiri dari 20 kecamatan dan 2 perwakilan kecamatan dengan jumlah desa 242 dan 8 kelurahan. Dari 22 kecamatan hanya ada 4 kecamatan yang merupakan kecamatan pesisir yaitu Kecamatan Blanakan, Kecamatan Pamanukan, Kecamatan Legon Kulon dan Kecamatan Pusakanegara. Dengan luas masingmasing kecamatan berturut-turut adalah $\left(85,81 \mathrm{~km}^{2}\right),\left(80,89 \mathrm{~km}^{2}\right),\left(98,47 \mathrm{~km}^{2}\right)$ dan $\left(68,40 \mathrm{~km}^{2}\right)$. Luas wilayah kecamatan pesisir Kabupaten Subang keseluruhannya adalah $333,57 \mathrm{~km}^{2}$ atau $16 \%$ dari luas seluruh Kabupaten Subang.

\section{Potensi Tambak}

Kabupaten Subang mempunyai panjang pantai mencapai $68 \mathrm{~km}$, sangat potensial untuk pengembangan usaha budidaya. Komoditas yang sangat cocok untuk dikembangkan adalah Rumput Laut (Euchema spp), Kakap (Lates carcarifer), Kerapu (Ephinephelus spp), Udang Windu (Penaeus monodon), Udang Putih (Penaeus marguensis), Bandeng (Channos channos) dan Kerang-kerangan serta jenis ikan lainnya. Seiring dengan besarnya peluang usaha tambak, maka peluang usaha pembenihan (hatchery) pun sangat luas. Tahun 2011 di Kabupaten Subang 
memiliki potensi lahan budidaya tambak seluas kurang lebih 14.300 ha yang terletak di lima kecamatan yaitu Blanakan, Pamanukan, Pusakanagara, Sukasari dan Legonkulon. Produksi udang di Subang tahun 2009 tercatat 3.143,50 ton, tahun 2010 sebanyak 2.004 ton, dan pada tahun 2011 produksi udang dari lahan budidaya tambak yang dimanfaatkan adalah sebesar 2.106,72 ton .

Daerah Pantura Subang saat ini akan dijadikan daerah industri penghasil Udang Vaname di Jawa Barat maupun tingkat Nasional. Tahap awal, saat ini lahan tambak bandeng sudah mulai dijadikan tambak udang untuk memenuhi permintaan nasional. Dijadikannya Pantura Subang sebagai daerah industri penghasil udang tidak terlepas dari program yang dicanangkan oleh Kementerian Kelautan dan Perikanan yang bertujuan untuk membangkitkan kembali masa keemasan tambak udang di daerah pantura dan meningkatkan kembali produksi udang yang sempat terpuruk. Guna mengoptimalkan kawasan pertambakan pantura di Kabupaten Subang, target industrialisasi lahan pertambakan udang di kawasan ini pada tahun 2012 adalah 719 ha. Untuk pencapaian target tersebut maka dilakukanlah revitalisasi tambak yang dilakukan adalah melalui perbaikan infrastruktur berupa saluran primer, sekunder dan tertier dan sekaligus perbaikan tambak.

\section{Kondisi Kawasan Pesisir Subang}

Pusat Pengelolaan Lingkungan Hidup (2007), perairan pantai Subang memiliki kedalaman yang relatif dangkal (kurang dari $20 \mathrm{~m}$ ) dengan gradien kedalaman yang relatif landai, dimana untuk kedalaman kurang dari $5 \mathrm{~m} \quad \mathrm{di}$ sekitar Blanakan gradiennya sekitar 0.0027 dan 0.0054 di sekitar Pusakanegara; di perairan antara $5-10 \mathrm{~m}$ gradien kedalaman berkisar antara 0.0006 (di sekitar Blanakan) sampai 0.0027 (di sekitar Pusakanegara). Hal ini berarti bahwa di bagian barat Pantai Subang (seperti Kecamatan Blanakan) lebih landai dibandingkan dengan di bagian timur Pantai Subang (seperti Kecamatan Pusakanegara). (Atlas Subang, 2002) Wilayah pantai Blanakan Subang yang berbentuk seperti teluk memungkinkan terjadinya proses pengendapan sedimen dari sungai dan dari angkutan sedimen pantai menjadi lebih besar, sehingga di wilayah ini laju pendangkalan perairan sangat besar. Dari hasil observasi lapangan diperoleh keterangan bahwa luas lahan timbul dari hasil pengendapan sedimen ini mencapai sekitar 400 Ha yang berada di sekitar muara sungai Blanakan. Di wilayah timur pantai Subang dengan garis pantai memanjang dalam arah tenggara - barat laut cenderung mengalami penggerusan garis pantai (abrasi).

Arus perairan di wilayah pantai Subang menunjukkan bahwa di perairan pantai Mayangan arus pasang berkisar 
antara $1.4 \pm 31.5 \mathrm{~cm} /$ det mengalir dominan ke arah barat, dan arus surut berkisar antara $0.7 \pm 28.1 \mathrm{~cm} /$ det yang mengalir dominan ke arah barat. Di lokasi pantai Ciasem arus pasang berkisar antara $1.5 \pm 30.7 \mathrm{~cm} /$ det yang dominan kearah barat,sedangkan arus surut berkisar antara $1.9 \mathrm{~cm} /$ det sampai $33.5 \mathrm{~cm} /$ det dominan kearah barat Puslitbang Pengairan, (1985) dalam PPLH (2007). Arah arus dominan ke arah barat pada waktu pasang maupun surut ini diperkirakan bahwa komponen arus musiman menjadi dominan di wilayah perairan ini.

Kabupaten Subang, menurut kajian Atmadipoera (2002) dalam PPLH (2007), Jenis pasut di lokasi ini memiliki nilai formzal $\mathrm{F}=(19.3+11.4) /(10.5+7.7)=$ 1.69 , berarti tipe pasut campuran yang condong ke harian tunggal dengan tunggang pasut adalah $61.4 \mathrm{~cm}$. Hal ini berarti dalam satu hari kadang-kadang terdapat hanya satu kali pasang dan satu kali surut, tetapi juga kadang terdapat dua kali pasang dan dua kali surut

Gelombang di sekitar pantai Mayangan dan Ciasem Subang dalam musim Peralihan (Mei) menunjukkan bahwa tinggi gelombang berkisar antara 4 $\mathrm{cm}$ sampai $42 \mathrm{~cm}$ dengan periode gelombang antara 2.0 sampai 6.5 detik. Arah rambatan gelombang yang dominan berasal dari arah Utara dan Timur laut. Di wilayah Pantai Ciasem tinggi gelombang berkisar antara $2.0 \mathrm{~cm}$ sampai $50 \mathrm{~cm}$, dengan periode gelombang antara 1.8 sampai 5.7 detik dan arah gelombang yang dominan adalah Utara dan Timur laut (Puslitbang Pengairan,1985) dalam PPLH (2007).

\section{Status Kualitas Perairan Subang}

Hasil pengukuran parameter kualitas perairan pesisir Kabupaten Subang disajikan pada Tabel 3.

Tabel 3. Kualitas Air di Lokasi Penelitian Tahun 2012

\begin{tabular}{|c|c|c|c|c|c|c|c|c|}
\hline Parameter & St 1 & St 2 & St 3 & St 4 & St 5 & St 6 & St 7 & St 8 \\
\hline $\mathrm{pH}$ & 7,65 & 8,10 & 7,66 & 8,20 & 7,85 & 8,25 & 7,95 & 8,25 \\
\hline Suhu & 30 & 31 & 30 & 31 & 31 & 32 & 31 & 32 \\
\hline Kecerahan & 35 & 60 & 35 & 62 & 30 & 55 & 30 & 57 \\
\hline Salinitas & 27 & 29 & 27 & 29 & 27 & 29 & 27 & 29 \\
\hline $\mathrm{DO}$ & 6,02 & 6,30 & 6,01 & 6,25 & 6,10 & 6,40 & 6,15 & 6,55 \\
\hline $\mathrm{NH}_{3}$ & 0,10 & 0,06 & 0,10 & 0,07 & 0,15 & 0,09 & 0,15 & 0,09 \\
\hline $\mathrm{COD}$ & 33,6 & 30,3 & 34,2 & 30,6 & 39,8 & 33,5 & 37,5 & 32 \\
\hline $\mathrm{BOD}$ & 11,2 & 10,3 & 11,4 & 10,8 & 16,9 & 14,5 & 15,5 & 14,2 \\
\hline
\end{tabular}

Dari parameter kualitas air dilakukan penilaian tingkat pencemaran perairan yang hasilnya terdapat pada Tabel 4 .
Pedoman yang digunakan untuk mengetahui tingkat pencemaran di perairan pantai Subang adalah Keputusan 
Menteri Negara Lingkungan Hidup Nomor : 115 Tahun 2003 tentang Pedoman Penentuan Status Mutu Air, yaitu mengenai Penentuan Status Mutu Air dengan Metoda Indeks Pencemaran. Dalam Keputusan Menteri Negara Lingkungan Hidup Nomor : 115 Tahun 2003 tentang Pedoman Penentuan Status Mutu Air, disebutkan bahwa Indeks Pencemaran (IP) adalah indeks yang digunakan untuk menentukan tingkat pencemaran relatif terhadap parameter kualitas air yang diizinkan. Indeks ini memiliki konsep yang berlainan dengan Indeks Kualitas Air. Indeks Pencemaran ditentukan untuk suatu peruntukan, kemudian dapat dikembangkan untuk beberapa peruntukan bagi seluruh bagian badan air atau sebagian dari suatu perairan. Nilai Indeks Pencemaran dapat dihitung dengan rumus :

$$
\mathrm{IP}_{\mathrm{x}}=\frac{\sqrt{\left(C \mathrm{Ci} / L \mathrm{i}_{x}\right)^{2}{ }_{M}+\left(C \mathrm{C} / L \mathrm{i}_{x}\right)^{2}} \mathrm{R}}{2}
$$

Dengan :

IPx $=$ Indeks Pencemaran peruntukan air $(\mathrm{x})$,

$\mathrm{Ci}=$ Konsentrasi parameter kualitas air (i) dari suatu perairan yang akan dinilai, Lix $=$ Konsentrasi parameter sesuai baku mutu air peruntukan $(\mathrm{x})$

$\mathrm{M}=$ Maksimum

$\mathrm{R}=$ Rata-rata

Evaluasi terhadap nilai Indeks Pencemaran adalah :

$0 \leq \mathrm{IP} \leq 1,0=$ Memenuhi baku mutu

(kondisi baik)

$1,0<\mathrm{IP} \leq 5,0=$ Cemar ringan

$5,0<\mathrm{IP} \leq 10,0=$ Cemar sedang

IP $>10,0=$ Cemar berat

Tabel 4. Indeks Pencemaran Perairan Subang

\begin{tabular}{|c|c|c|c|c|c|}
\hline No & Parameter & Satuan & $\begin{array}{c}\text { Ci rata- } \\
\text { rata }\end{array}$ & Lix & Ci/Lix \\
\hline 1 & Suhu & ${ }^{\circ} \mathrm{C}$ & 31 & 30 & 1,0333 \\
\hline 2 & $\mathrm{TSS}$ & $\mathrm{Mg} / 1$ & 238 & 80 & 2,975 \\
\hline 3 & $\mathrm{pH}$ & - & 7,9 & 8,5 & 0,9294 \\
\hline 4 & $\mathrm{Salinitas}$ & $\%$ oo & 28 & 33 & 0,8484 \\
\hline 5 & $\mathrm{DO}$ & $\mathrm{Mg} / 1$ & 6,22 & 5 & 1,244 \\
\hline 6 & $\mathrm{BOD}$ & $\mathrm{Mg} / 1$ & 13,1 & 20 & 0,655 \\
\hline 7 & $\mathrm{COD}$ & $\mathrm{Mg} / 1$ & 34,11 & 40 & 0,8527 \\
\hline
\end{tabular}

Ci/Lix rata-rata $=0,7959$

$\mathrm{Ci} /$ Lix Maksimum $=2,975$

$\mathrm{IP}=2,2491$

$\mathrm{IP}=\frac{\sqrt{\left(\mathrm{Ci} / \mathrm{Li}_{\mathrm{x}}\right)^{2} \mathrm{M}+\left(\mathrm{Ci} / \mathrm{Li}_{\mathrm{x}}\right)^{2} \mathrm{R}}}{2}$ 
Berdasarkan perhitungan, nilai Indeks Pencemaran $(2,2491)$ maka dapat disimpulkan bahwa perairan Pantai Subang tercemar ringan.

Beban pencemaran limbah organik di dasar perairan penting untuk diperhatikan dalam pengelolaan budidaya . Hal ini terkait dengan penataan unit budidaya pada suatu kawasan agar tidak berdampak negatif. Menurut Rachman Syah (2006), budidaya udang Vannamei dengan kepadatan 50 ekor $/ \mathrm{m}^{2}$ beban limbah yang dihasilkan mencapai 286,66 $\mathrm{kg} \mathrm{N}$ dan 283,84 $\mathrm{kg} \mathrm{P}$ pada tingkat produksi $5.277 \mathrm{~kg} / \mathrm{ha}$. Beban limbah perikanan budidaya sangat ditentukan oleh nilai Rasio Konversi Pakan, kualitas pakan, dan retensi nutrien pada organisme yang dibudidayakan.

\section{Indeks Diversitas Plankton}

Hasil analisis komunitas plankton pada 8 (delapan) stasiun pengambilan contoh di perairan pantai Subang, masingmasing stasiun menunjukkan bahwa jumlah taksa berkisar antara 5 hingga 11 jenis, dengan kelimpahan total berkisar antara 490 hingga 1040 individu/liter. Hasil penghitungan indeks diversitas menunjukkan bahwa tingkat keanekaragaman komunitas plankton secara keseluruhan tergolong sangat rendah dan rendah yakni dari 0,3578 sampai 1,1235. Hal ini menunjukkan bahwa perairan pesisir Kabupaten Subang sudah tercemar, sejalan dengan nilai Indeks pencemaran 2,2491 yang menunjukkan bahwa perairan Pantai Subang tercemar ringan. Menurut teori Shannon Winner, hubungan antara indeks keanekaragaman spesies dengan tingkat pencemaran dapat dilihat pada Tabel 5.

Tabel 5. Rangkuman hasil analisis sampel plankton

\begin{tabular}{|c|c|c|c|c|}
\hline Stasiun & $\begin{array}{c}\text { Kelimpahan } \\
\text { Total(Sel/Liter) }\end{array}$ & $\begin{array}{c}\text { Jumlah } \\
\text { Taksa }\end{array}$ & $\begin{array}{c}\text { Indeks } \\
\text { Diversitas }\end{array}$ & $\begin{array}{c}\text { Kriteria Kualitas } \\
\text { Air }\end{array}$ \\
\hline Stasiun 1 & 980 & 8 & 0,3578 & Sangat Rendah \\
\hline Stasiun 2 & 1040 & 11 & 1,1235 & Rendah \\
\hline Stasiun 3 & 720 & 8 & 1,0346 & Rendah \\
\hline Stasiun 4 & 950 & 10 & 1,0381 & Rendah \\
\hline Stasiun 5 & 490 & 5 & 0,6713 & Sangat Rendah \\
\hline Stasiun 6 & 520 & 7 & 0,9536 & Sangat Rendah \\
\hline Stasiun 7 & 660 & 7 & 0,7999 & Sangat Rendah \\
\hline Stasiun 8 & 940 & 9 & 0,8796 & Sangat Rendah \\
\hline
\end{tabular}




\section{Analisis Produktivitas Tambak Berdasarkan kelimpahan plankton dengan}

Klorofil a

Pada hubungan kelimpahan plankton terhadap klorofil-a didapatkan persamAan $\mathrm{Y}=0,01+0,000262 \mathrm{X}\left(\mathrm{R}^{2}: 0,79\right)$. (Diolah dari data Handayani dan Patria, 2005).

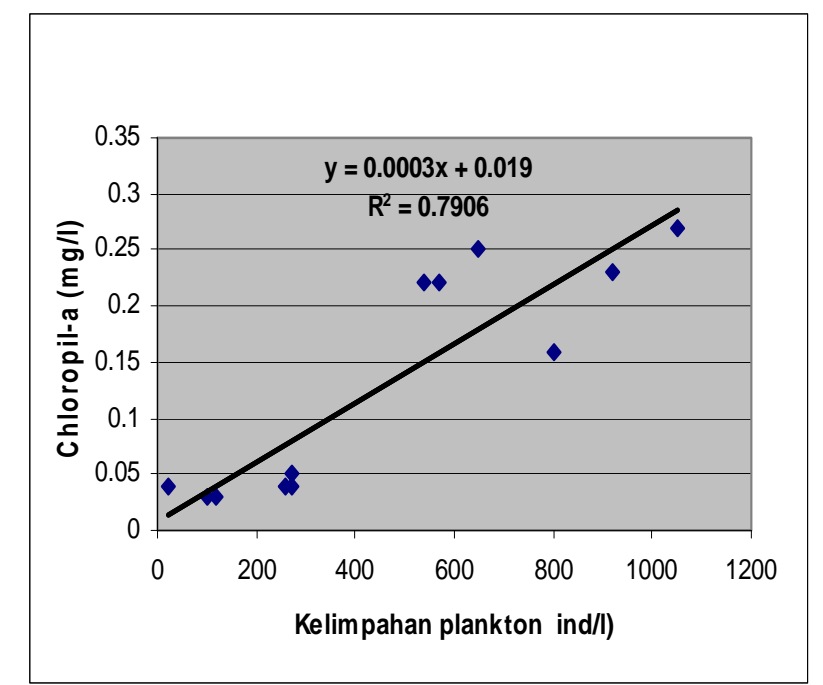

Gambar 2. Hubungan antara Kelimpahan Plankton dengan Klorofil a.

Dari Persamaan diatas, data klorofil dapat di hitung. Data klorofil selanjutnya di estimasi produktivitas primer mikroalgae. dengan melakukan konversi klorofil-a dengan mengalikan dengan asumsi nilai P/B rasio yaitu 146,9 dan Ekotropik Efisiensi 0,279 .

Tabel 6. Perhitungan Produktivitas Mikroalga

\begin{tabular}{|c|c|c|c|c|c|c|}
\hline $\begin{array}{c}\text { Kelimpaha } \\
\begin{array}{c}\text { n } \\
\text { Plankton } \\
\text { (Sel/Liter) }\end{array}\end{array}$ & $\begin{array}{c}\text { Klorof } \\
\text { il a } \\
(\mathbf{m g} / \mathbf{l})\end{array}$ & \multicolumn{4}{|c|}{ Biomas } & $\begin{array}{c}\text { Produktivitas } \\
\text { Mikroalgae } \\
\text { ton/ha/tahun }\end{array}$ \\
\cline { 3 - 6 } & & $\mathbf{\mu g} / \mathbf{l}$ & $\mathbf{m g / m 3}$ & $\mathbf{g} / \mathbf{m} \mathbf{2 / h a r i}$ & ton/ha/tahun & \\
\hline 980 & 0,27 & 270 & 2,43 & 0,16281 & 0,594256 & 87,3 \\
\hline 1040 & 0,28 & 280 & 2,52 & 0,16884 & 0,616266 & 90,5 \\
\hline 720 & 0,19 & 190 & 1,71 & 0,11457 & 0,418180 & 61,43 \\
\hline 950 & 0,26 & 260 & 2,34 & 0,15678 & 0,572247 & 84,06 \\
\hline 490 & 0,13 & 130 & 1,17 & 0,07839 & 0,286123 & 42,03 \\
\hline 520 & 0,14 & 140 & 1,26 & 0,08442 & 0,308133 & 45,26 \\
\hline 660 & 0,17 & 170 & 1,53 & 0,10251 & 0,374161 & 54,96 \\
\hline 940 & 0,25 & 250 & 2,25 & 0,15075 & 0,550237 & 80,82 \\
\hline
\end{tabular}


Dari hasil perhitungan didapatkan nilai produktivitas primer mikroalga rata-rata adalah 68,29 ton/ha/tahun.

Tabel 7. Estimasi Laju Produksi Perikanan Potensial

\begin{tabular}{|c|c|c|c|c|c|c|}
\hline No & $\begin{array}{c}\text { Biomass } \\
\text { Mikroalga } \\
\text { (ton/ha.th) }\end{array}$ & $\begin{array}{c}\text { Koefisien } \\
\mathbf{P} / \mathbf{B}\end{array}$ & $\begin{array}{c}\text { Produktivitas } \\
\text { Mikroalga } \\
\text { (ton/ha.th) }\end{array}$ & $\mathbf{E E}$ & $\begin{array}{c}\text { Mikroalga } \\
\text { yang di } \\
\text { Konsumsi } \\
\text { (ton/ha/th) } \\
\mathbf{E}=\mathbf{C} \mathbf{x} \mathbf{~ D )}\end{array}$ & $\begin{array}{c}\text { Laju } \\
\text { Produksi } \\
\text { Perikanan } \\
\text { Potensial } \\
\text { (ton/ha/th) } \\
\mathbf{( F = ~ E ~} \mathbf{x} \\
\mathbf{0 , 0 0 7})\end{array}$ \\
\hline 1 & 0,594256 & 146,9 & 87,3 & 0,279 & 24,35 & 0,17045 \\
\hline 2 & 0,616266 & 146,9 & 90,5 & 0,279 & 25,24 & 0,17668 \\
\hline 3 & 0,418180 & 146,9 & 61,43 & 0,279 & 17,13 & 0,11991 \\
\hline 4 & 0,572247 & 146,9 & 84,06 & 0,279 & 23,45 & 0,16415 \\
\hline 5 & 0,286123 & 146,9 & 42,03 & 0,279 & 11,72 & 0,08204 \\
\hline 6 & 0,308133 & 146,9 & 45,26 & 0,279 & 12,62 & 0,08834 \\
\hline 7 & 0,374161 & 146,9 & 54,96 & 0,279 & 15,33 & 0,10731 \\
\hline 8 & 0,550237 & 146,9 & 80,82 & 0,279 & 22,54 & 0,15778 \\
\hline
\end{tabular}

Dari estimasi perhitungan potensi perikanan didapatkan laju perikanan potensial rata-rata sekitar 0,13333 ton/ha/tahun. Dengan luas tambak pada Kabupaten Subang seluas 14.300 ha maka diperkirakan potensi produksi udang sebesar 1906,6 ton/tahun. Sedangkan Produksi udang di Subang tahun 2009 tercatat $3.143,50$ ton, tahun 2010 sebanyak 2.004 ton, dan pada tahun 2011 produksi udang dari lahan budidaya tambak yang dimanfaatkan adalah sebesar 2.106,72 ton, maka dengan demikian terjadi penurunan produksi udang tahun 2012.

Tambak di pesisir kabupaten Subang sebagian besar adalah tambak tradisional, hal ini dapat dilihat dari pengelolaan air tambak yang hanya tergantung dari pasang surut air laut saja, pakan juga masih tergantung dari alam. Pada tambak yang dikelola secara tradisional, udang hanya memakan berbagai jenis pakan alami yang ada didalam tambak, sehingga dengan tingginya nilai TSS, efek buruk pada ekosistim adalah rendahnya fotosintesa pada tambak yang mempengaruhi tersedianya pakan alami untuk udang. Laju pertumbuhan plankton sangat dipengaruhi oleh ketersediaan cahaya di dalam perairan. Partikel lumpur akan menghalangi penetrasi cahaya yang menyebabkan laju pertumbuhan plankton mengalami penurunan. Dengan berkurangnya plankton, nilai klorofil-a juga akan berkurang sehingga menimbulkan sifat kanibalisme. 
Berdasarkan penelitian Nontji (1984), nilai rata-rata kandungan klorofil di perairan Indonesia sebesar $0,19 \mathrm{mg} / \mathrm{m} 3$. Di laut, sebaran klorofil-a lebih tinggi konsentrasinya pada perairan pantai dan pesisir, serta rendah di perairan lepas pantai. Tingginya sebaran konsentrasi klorofil-a di perairan pantai dan pesisir disebabkan karena adanya suplai nutrien dalam jumlah besar melalui run-off dari daratan, sedangkan rendahnya konsentrasi klorofil-a di perairan lepas pantai karena tidak adanya suplai nutrien dari daratan secara langsung. Kandungan klorofil-a dapat digunakan sebagai ukuran banyaknya fitoplaknton pada suatu perairan tertentu dan dapat digunakan sebagai petunjuk produktivitas perairan.

$$
\text { Mina hutan (sylvofishery) }
$$

merupakan pola pendekatan teknis yang cukup baik, yang terdiri atas rangkaian kegiatan terpadu antara kegiatan budidaya dengan kegiatan penanaman, pemeliharaan, pengelolaan dan upaya pelestarian hutan mangrove. Sistem ini memiliki teknologi sederhana, yaitu memanfaatkan fungsi ekosistem mangrove sebagai biofilter polutan sehingga dapat menghasilkan atau meningkatkan kesuburan tanah tambak dan memudahkan tumbuhnya plankton sebagai sumber makanan alami udang.

\section{KESIMPULAN DAN SARAN}

\section{Kesimpulan}

1. Berdasarkan nilai indeks pencemaran dan indeks diversitas plankton maka dapat disimpulkan bahwa perairan pesisir Subang tercemar ringan.

2. Dari estimasi perhitungan potensi perikanan didapatkan laju perikanan potensial ratarata sekitar 0,13333 ton/ha/tahun. Dengan luas tambak seluas 14.300 ha maka diperkirakan potensi produksi udang Kabupaten Subang sebesar 1906,6 ton/tahun

\section{Saran}

1. Diperlukan penyuluhan kepada para pembudidaya dalam melakukan kegiatan budidaya udang di wilayah pesisir Kabupaten Subang dengan menggunakan pola silvofishery dengan memanfaatkan fungsi ekosistem mangrove untuk mengurangi pencemaran perairan

2. Untuk menjaga kelestarian sumberdaya diwilayah pesisir kabupaten Subang disarankan untuk tidak menambah luasan tambak dan pengelolaan tambak menggunakan sistim tradisional. 


\section{DAFTAR PUSTAKA}

Dahuri, R. 2001. Pengelolaan Sumberdaya Wilayah Pesisir dan Lautan Secara Terpadu. 328 hal

Handayani, S, dan Patria M.P. 2005. Komunitas Zooplankton di Perairan Waduk Krenceng Cilegon ,Banten. Makara Sains, Vol. 9 No. 2. November 2005: 75 - 80 .

Marganof, 2007. Model Pengendalian Pencemaran Perairan di Danau Maninjau Sumatra Barat. IPB. Bogor.

Nontji, A. (1984), Biomassa dan Produktivitas Fitoplankton di Perairan Teluk Jakarta Serta Kaitannya dengan Faktorfaktor Lingkungan.

Disertasi.Fakultas Pascasarjanan. Institut Pertanian Bogor

Nybakken, J. W. (1992), Biologi Laut: Suatu Pendekatan Ekologis. Diterjemahkan oleh H. M. Eidman, Koesoebiono, D. G. Bengen, M. Hutomo dan S. Subarjo. PT. Gramedia Pustaka Utama. Jakarta.
Poole, R.W. 1974. An Introduction to Quantitative Ecology. Mc. Graw Hill Kogakusha, Ltd. Tokyo. 325 Pages

PKSPL, 2002. Kajian Kegiatan Tambak Dalam Hubungannya Dengan Kegiatan Migas dan Lingkungan Hidup di Delta Mahakam. PKSPL - IPB. Bogor.

PPLH.2007. Kajian Lingkungan Hidup Wilayah Pantai Utara Pulau Jawa.

Rachman Syah . dkk. 2006. Pendugaan Nutrient Budget Tambak Intensif Udang Litopenaeus Vannamei. Jurnal Riset Akuakultur Vol. 1, No.2 : 181202.

Sapto, A. 2008 Studi Sedimen Melayang dan Dampaknya terhadap Produktivitas Perikanan (Studi Kasus Muara Sungai Porong). ITS. Surabaya.

Soegianto, A. 2004. Metode Pendugaan Pencemaran Perairan Dengan Indikator Biologis. Airlangga University Press. Surabaya.

Widigdo,B. (2001). Perencanaan dan Pengelolaan Budidaya Perairan Wilayah Pesisir. PKSPL - IPB. Bogor 